\title{
COMBINING SATELLITE ALTIMETRY, TIME-VARIABLE GRAVITY, AND BOTTOM PRESSURE OBSERVATIONS TO UNDERSTAND THE ARCTIC OCEAN: A TRANSFORMATIVE OPPORTUNITY
}

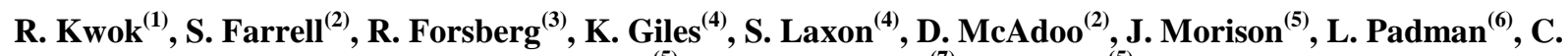 \\ Peralta-Ferriz $^{(5)}$, A. Proshutinsky ${ }^{(7)}$, M. Steele ${ }^{(5)}$ \\ ${ }^{(1)}$ Jet Propulsion Laboratory, California Institute of Technology, 4800 Oak Grove Dr, Pasadena, CA 91109, USA, \\ Email: ron.kwok@jpl.nasa.gov \\ ${ }^{(2)}$ NOAA (National Oceanic and Atmospheric Administration) Laboratory for Satellite Altimetry, Silver Spring, MD \\ 20910 USA, Email: sinead.farrell@noaa.gov; dave.mcadoo@noaa.gov \\ ${ }^{(3)}$ Geodynamics Department, Danish National Space Center, Juliane Maries Vej 30, DK-2100, Copenhagen O, DK, \\ Email: rf@space.dtu.dk \\ ${ }^{(4)}$ Centre for Polar Observations and Modelling, University College London, Gower Street, London WCIE 6BT, UK \\ Email: k.giles@cpom.ucl.ac.uk; swl@cpom.ucl.ac.uk \\ ${ }^{(5)}$ Polar Science Center, Applied Physics Lab, University of Washington, 1013 NE 40th St, Seattle, WA 98105-6698, \\ USA,Email:morison@apl.washington.edu; ferriz@u.washington.edu; mas@apl.washington.edu \\ ${ }^{(6)}$ Earth \& Space Research, Corvallis, OR 97333 USA, Email: padman@esr.org \\ ${ }^{(7)}$ Woods Hole Oceanographic Institution, 86 Water St, Woods Hole, MA 02543-1052, USA,
}

Email:proshutinsky@whoi.edu

\begin{abstract}
New developments in our observational capabilities present an unprecedented opportunity to make significant progress towards an integrated ability to address scientific issues of both the ocean and ice components of the Arctic Ocean system. In the coming decade, data from gravity satellites (GRACE (Gravity Recovery And Climate Experiment) and GOCE (Gravity and Steady State Ocean Circulation Explorer)), and polar-orbiting altimeters (e.g. ENVISAT (Environmental Satellite), ICESat (Ice, Cloud, and land Elevation Satellite), and upcoming CryoSat-2 (CRYOgenic SATellite), ICESat-2, and SWOT (Surface Water Ocean Topography)) will provide basin-scale fields of gravity and surface elevation. Together with an optimally designed in-situ hydrographic observation network, these data sets will have the potential to significantly advance our understanding of the iceocean interactions, circulation and mass variations of the Arctic Ocean. Recent work has demonstrated the combined use of GRACE and bottom pressure recorder (BPR) data for understanding the Arctic circulation, and the use of high precision altimeters for documenting recent decline in sea ice thickness. We describe several topics of particular interest in the use of satellite and insitu data, and the considerations for the design of an observational network for hydrographic sampling.
\end{abstract}

\section{INTRODUCTION}

Although hydrographic observations - and some oceanographic models - indicate substantial changes in the Arctic Ocean's general circulation since 1980, such observations are sparse. In consequence, the circulation of the Arctic Ocean is poorly understood relative to that of lower latitude oceans. However, integrated analyses of new data from in-situ hydrographic observations, gravity satellites (GRACE (Gravity Recovery And Climate Experiment) and the upcoming GOCE (Gravity and Steady State Ocean Circulation Explorer)), and polar-orbiting altimeters (e.g. ENVISAT (Environmental Satellite), ICESat ICESat (Ice, Cloud, and land Elevation Satellite), and upcoming CryoSat-2 (CRYOgenic SATellite) and ICESat-2) show promise of redressing our poor understanding of the Arctic Ocean circulation and mass variations. Satellite altimeters observe the total sea level variation, including the signal caused by temperature and salinity fluctuations (the steric effect) and non-steric barotropic and mass variations. Separately, gravity satellites like GRACE measure temporal changes in the Earth's gravity field caused by the movement of water masses. Together with an optimally designed bottom pressure array for resolving shorter time scale processes, the steric (halosteric and thermosteric) and non-steric effects can be separated for quantifying changes in circulation and variability in Arctic sea level. Furthermore, sea surface heights from altimetry when differenced with the mean Arctic satellite geopotential constrain the geostrophic circulation.

While the sea-ice extent of the Arctic Ocean has been monitored for over 30 years, there is a paucity of timevarying ice thickness data available for estimating the ice volume/thickness changes needed for improved understanding of ice-ocean interactions. With altimetry data from the ERS (European Remote-Sensing Satellite), ENVISAT, and ICESat missions, Laxon et al. [1] and Kwok et al. [2] have demonstrated that fields of sea ice freeboard and thickness can be extracted. The upcoming CryoSat-2 (launch date: late 2009) and 
ICESat-2 (planned launch: 2014) missions, both with primary scientific objectives of addressing changes in the thickness of Arctic sea ice, will provide extensive coverage of the Arctic Ocean into the next decade.

In this paper we demonstrate recent progress in quantifying seasonal to decadal basin scale changes of the Arctic Ocean, using combinations of satellite gravity and altimetry data, concurrent in-situ measurements of ocean hydrography, bottom pressure and ice thickness, and airborne marine gravity surveys. These initial steps lead us to propose that significant further advances in our understanding of Arctic Ocean and sea-ice variability on seasonal to decadal time scales can be achieved by an integrated, interdisciplinary approach to data collection and interpretation. This progress requires a sustained observational network of repeat hydrographic sampling, sea surface height, bottom pressure and sea ice thickness to complement existing and planned satellite missions. We highlight five research topics that demonstrate the progress that we can expect: 1) Arctic Ocean circulation change from satellite gravity, bottom pressure recorders and hydrography; 2) marine gravity and dynamic topography from altimetry; 3 ) improvement of Arctic tide models; 4) sea ice thickness and volume; and, 5) description and rationale for an in-situ observational network to complement the satellite fields. Figure 1 shows the terminology and geometry of the sea surface used in this paper.

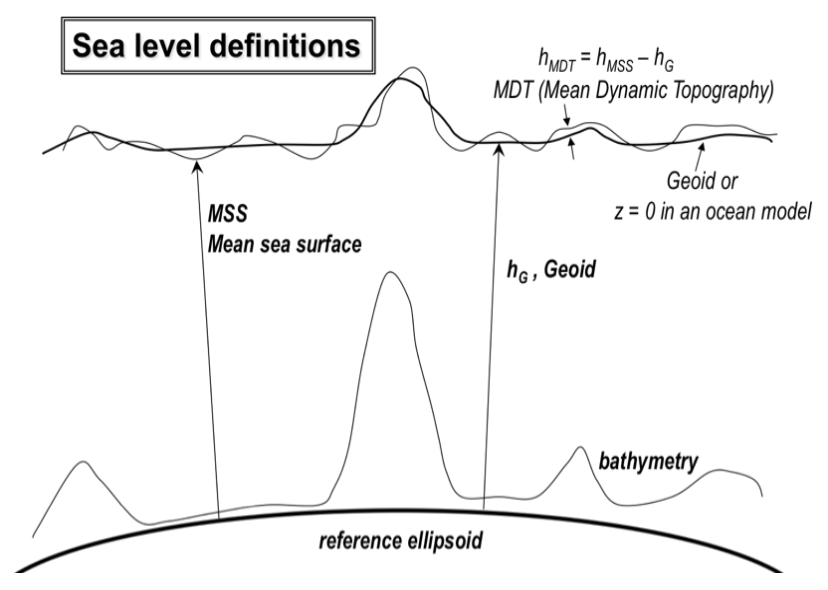

Figure 1. Sea level geometry and terminology used in the text.

\section{ARCTIC OCEAN CIRCULATION CHANGES FROM GRACE, BOTTOM PRESSURE RECORDERS, AND HYDROGRAPHY}

Morison et al. [3] recently illustrated the potential of synthesis of hydrographic observations and satellite time-variable gravity for detection of changes in Arctic Ocean circulation. The study showed that GRACEderived bottom pressure (BP) trends in the capture important time-scale shifts in Arctic Ocean circulation and an ongoing trend of freshening in the western Arctic. These appear to be associated with the atmospheric circulation of the whole Northern Hemisphere and climate-related changes in the Arctic ice cover.

At the North Pole, the GRACE Release 4 (R4 - an improved data set) values of bottom pressure [4] (Fig. 2) show excellent agreement with in-situ observations from Arctic Bottom Pressure Recorders (ABPR; [3]). Also, as shown for GRACE R1 by Morison et al. [3], the declining trend in GRACEderived BP at the North Pole from 2002 to 2006 agrees with the measured decline in ocean mass due to the decrease in ocean density associated with the advance of lower salinity, Pacific-derived water into the region [3]. Most recently, GRACE R4 data show a rising BP trend at the Pole from 2005 to 2008 that can be explained by the measured steric increase due to reappearance of more saline, Atlantic-derived water. The correspondence between measured steric and BP trends is consistent with the idea that changes in $\mathrm{BP}$ at long time-scales are dominated by steric changes as opposed to sea surface height changes [5].

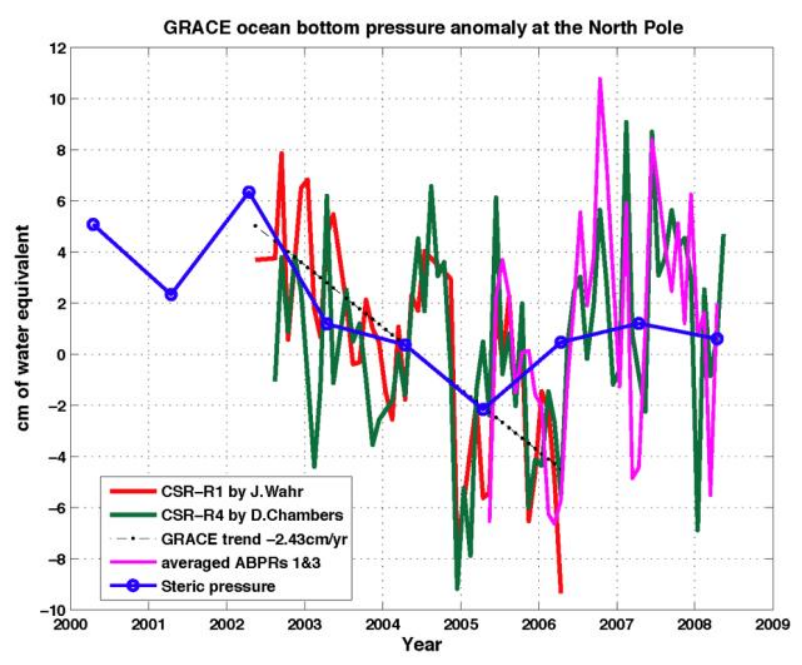

Figure. 2 Bottom pressure from GRACE Releases 1 and 4 along with averages of $A B P R$ records.

Absolute values are arbitrary and have been set to zero for Release 4. Other record averages are matched to Release 4. The steric variation due to ocean mass changes from hydrographic observations in the top $200 \mathrm{~m}$ within $200 \mathrm{~km}$ of the Pole is also shown.

Considering the whole basin, GRACE R4 BP trends 2002-06 (Fig. 3 left, modified from Fig. 4 of Morison et al. [3] to incorporate GRACE R4) in the central Arctic Ocean agree with GRACE R1 trends in showing a pressure decline particularly in the Makarov Basin between the Alpha-Mendeleyev Ridge and Lomonosov Ridge. There, as with R1, the R4 trends agree with the trends represented by the circles colored according to the hypothetical steric trends that would apply if the hydrography returned, over 6 years, from conditions measured in 1993 at those locations to pre-1990s climatology [EWG, 1997]. Sea surface height trends 
(colored triangles in Fig. 3), calculated as the difference between the bottom and steric pressure trends, suggest a clockwise shift of the Transpolar Drift that roughly agrees with changes in ice drift from 2000 to 2005. The result is consistent with the hypothesized return from the cyclonic hydrographic pattern of the 1990s to the anticyclonic pattern of pre-1990s climatology [3 and 4].

GRACE R4 (unlike R1) trends 2002-2006 are opposite to the hypothesized trends in the Beaufort Sea, where GRACE shows a decline in bottom pressure. However, the GRACE trends agree with observed steric trends (colored squares) in the Beaufort Sea from the hydrographic measurements of the Beaufort Gyre Exploration Project (BGEP) and in the central Arctic from the North Pole Environmental Observatory (NPEO derived water across the Lomonosov Ridge. However, declining trends in BP in the Beaufort Sea (red ellipses) due to declining salinity persisted and actually accelerated in 2007-08. This is indicative of a growing lens of low salinity surface water in the eastern Canada Basin (green ellipse) consistent with hydrographic observations in Spring 2008.

The changes in the Arctic Ocean hydrography in the last two years are nearly as dramatic as those in the 1990s, but with a different character. The 1990s were largely characterized by the shift to a more cyclonic circulation. Morison et al. [3] argue that the anticyclonic circulation shift in 2002-2006, exemplified by the GRACE data, was related to a decrease in the Arctic Oscillation (AO) index, an expression of the strength of the cyclonic
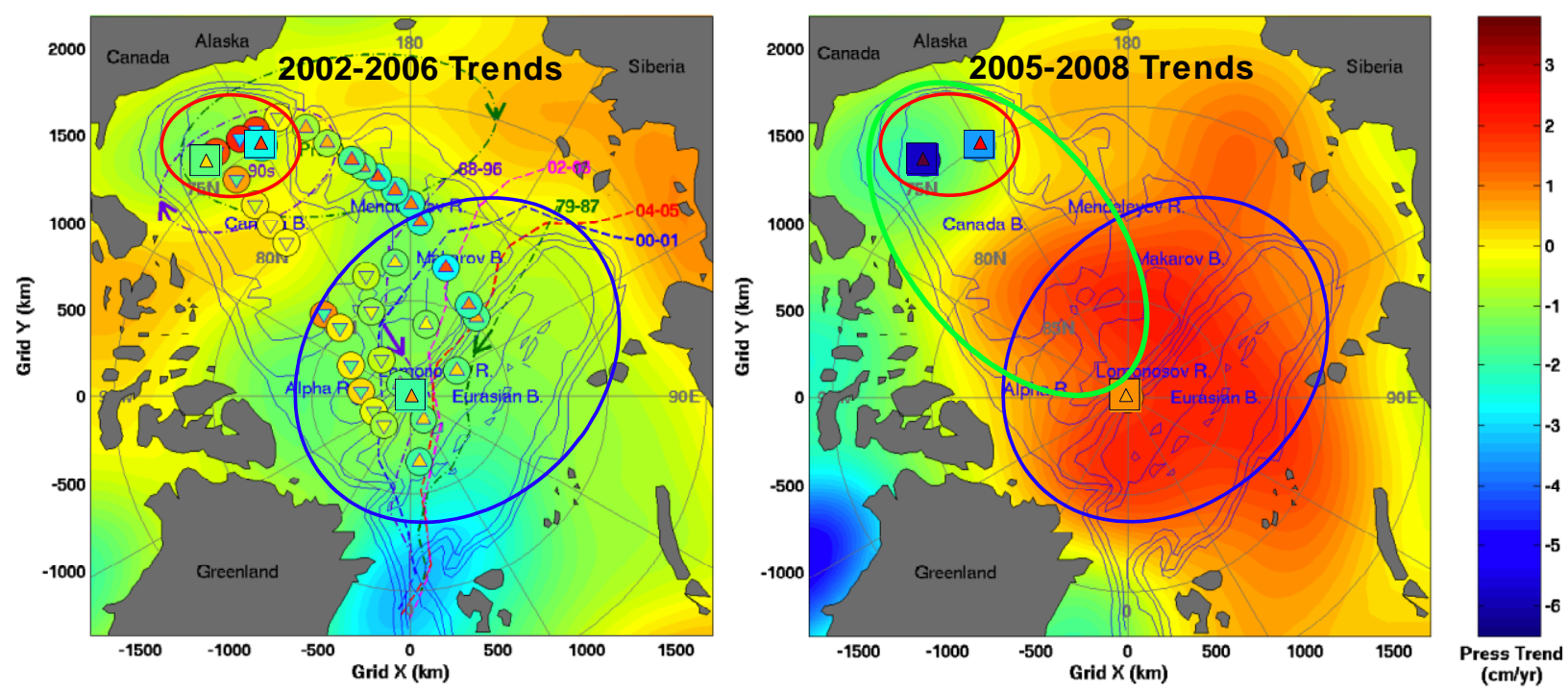

Figure. 3 GRACE Release 4 bottom pressure trends, 2002-06 (left) and 2005-08 (right), in the Arctic Ocean. Colored circles (left) represent trends associated with a hypothesized return to climatology from conditions of the 1990s

(from Morison et al., 2007 [3]). Also shown are the steric trends from hydrographic observations (colored squares) and the sea surface height trends (colored triangles) calculated as the difference between the bottom and steric pressure trends. The declining bottom pressure trend, 2002-06, in the central Arctic (blue ellipse) illustrates the anticyclonic advance of relatively fresh (light) Pacific-derived water across the basin, and the rising trend, 2005-08,

is associated with a cyclonic advance of salty Atlantic-derived water. Declining trends in bottom pressure in the

Beaufort Sea (red ellipses) due to declining salinity persist throughout and in 2007-08 accelerated to produce a growing lens of low salinity surface water in the eastern Canada Basin (green ellipse). From Morison et al. (2007 \& 2008 [6]).

(North Pole Environmental Observatory (National Science Foundation)). The associated sea surface height trends were small during 2002-2006 except in the Beaufort Sea, where sharply declining steric trends due to decreasing salinity were partly offset by a rise in sea surface height associated with the buildup and westward shift of the anticyclonic Beaufort Gyre.

The rising bottom pressure trend from 2005 to 2008 (Fig. 3 right) in the central Arctic is consistent with a rise in salinity observed there in most of the upper ocean by the NPEO and illustrated by the colored square at the Pole. This is arguably associated with a cyclonic advance of more saline (heavier) Atlantic- atmospheric polar vortex in the Northern Hemisphere [7].

The most recent changes in bottom pressure are characterized by a cyclonic shift in the Central Arctic Ocean and Eurasian Basin, with a strong anticyclonic change in the eastern part of the Canada Basin. The GRACE bottom pressure trends in the central Arctic Ocean from 2005 to 2008 are associated with high winter AO index and record and near-record minima in September ice extent in 2007 and 2008. In contrast, the declining pressure due to accumulation of the freshwater lens in the Beaufort Sea appears to be associated with a strong Beaufort High anticyclonic 
atmospheric circulation in the summer of 2007, which caused ice and upper ocean freshwater convergence through Ekman dynamics. The sense of this forcing is opposite to that characterizing the central and Eurasian Arctic for the same period.

Thus far, we are only beginning to understand the full utility of time-varying gravity for studying the Arctic Ocean. A longer record of GRACE results coupled with routine sea surface height measurements and an in-situ hydrographic sampling network, as described in the following sections, is crucial for providing a more synoptic view of the Arctic Ocean for advances in documenting the large scale changes in the Arctic's ocean and ice components.

\section{GRAVITY TOPOGRAPHY FIELD FROM AND DYNAMIC OBSERVATIONS SATELLITE}

\subsection{Need for an accurate Mean Gravity Field or Geoid}

A very accurate high-resolution model of the earth's geoid is particularly important for Arctic satellite oceanography. In fact, a more accurate marine geoid is needed to recover the absolute mean dynamic topography (MDT) in the Arctic than for any other major ocean basin. Two things give rise to this particularly challenging Arctic geoid requirement: (1) the relatively small extent of the Arctic Ocean basin in addition to the smaller length scales of ocean variability here (e.g. small Rossby radius of deformation), and (2) the relatively small amplitude (much less than $1 \mathrm{~m}$ ) of Arctic MDT at sub-basin scales.

By definition, the geoid is the gravitational equipotential surface that as a level surface is everywhere horizontal. On an idealized earth devoid of ocean and rotational dynamics, the geoid would most closely conform to the mean sea surface (MSS). In reality, the MSS (averaged over yearly-or-longer time spans) and the geoid generally differ by no more than about two meters whereas the amplitude of geoid and MSS variations are both of order $100 \mathrm{~m}$. With a precise geoid, one can compute the MDT by taking the difference between an altimetric MSS and the geoid as detailed below (Sect. 3.2). A state-of-the-art EGM2008 geoid derived from GRACE and surface data for the Arctic Ocean, shown in Fig. 4, appears to be nearly identical to the altimetric MSS (not shown). Indeed, the differences between the Arctic geoid and MSS are small $(<1 \mathrm{~m})$ and represent MDT plus errors. Shortwavelength errors $(<400 \mathrm{~km}$; i.e., GRACE spatial resolution) of order $10-30 \mathrm{~cm}$ in the Arctic geoid and/or MSS (Mean-Square Slope) must be resolved if we are to precisely map the steady-state Arctic Ocean circulation. A new gravity satellite, GOCE, launched on March 17, 2009, should produce important reductions in these Arctic Ocean geoid errors.

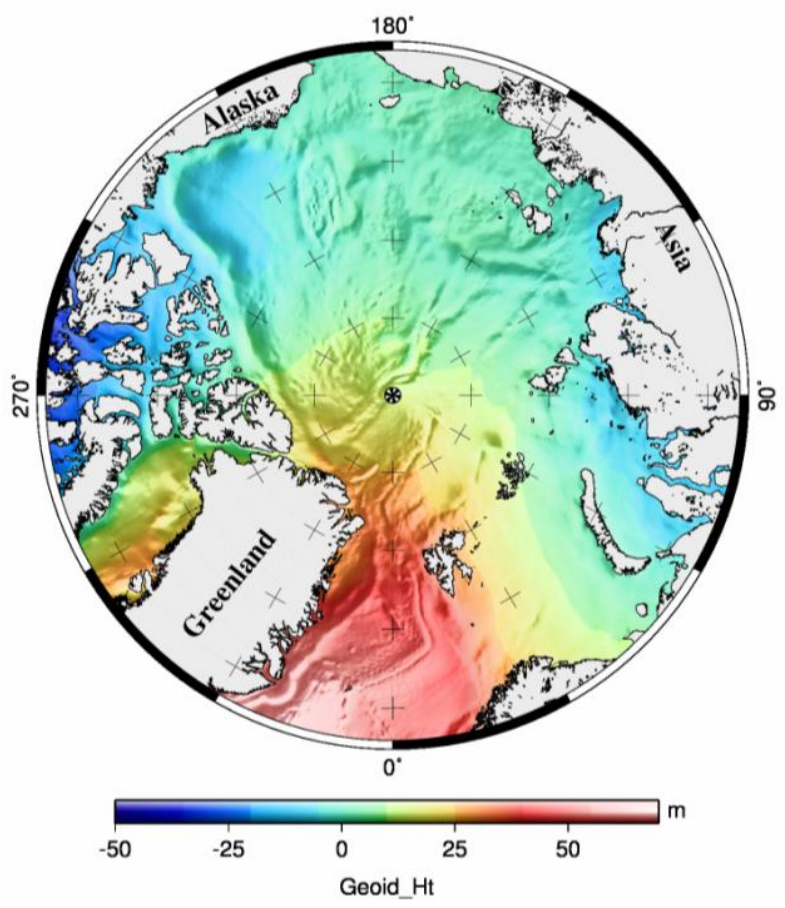

Fig. 4 Geoid of the Arctic Ocean from GRACE and surface gravity data computed from EGM2008 /81

\subsection{Dynamic topography from satellite altimetry}

The MDT, which is generally reported relative to a specific averaging period, is important as it provides information essential to mapping total geostrophic circulation, and is one of the simplest practical validations of ocean models. Typically, MDT is derived thus:

$$
h_{M D T}=h_{M S S}-h_{G} .
$$

Here, $h_{M S S}$ is the satellite altimetric measurement of mean sea surface height averaged in time, $h_{G}$ is the modeled geoid height, and $h_{M D T}$ is the mean dynamic topography. Extracting MDT is therefore dependent on a precise geoid model and an accurate and detailed map of the MSS. Dedicated gravity missions such as CHAMP (CHAllenging Mini-Satellite Payload), GRACE, and the recently-launched GOCE, are providing new data that allow for the computation of improved geoids with higher spatial resolution compared to previous geopotential models. Recent work on this topic has revealed the amplitude of the dynamic ocean topography as well as the zonal and meridional geostrophic currents of the global oceans to $82^{\circ} \mathrm{N}$ and $\mathrm{S}$ (e.g. [9]).

For the Arctic Ocean, knowledge of the MDT remains poorly constrained. While polar-orbiting satellite altimeters provide sea surface height measurements, both spatial and temporal coverage of the high Arctic has thus far been limited. Furthermore, the direct measurement of sea surface height is impeded by the 
presence of sea ice, and short wavelength errors that still exist in the geoid prevent the investigation of mesoscale ocean features. Initial analysis indicates however that by combining the best available mean sea surface height fields from the ERS and ICESat satellite data sets, with a state-of-the-art geoid (e.g. EGM08, Fig. 4), large-scale MDT structure, such as the Beaufort Gyre, may be observed. The recent ARCGICE project (Forsberg et al., 2007 [10]) explored models of Arctic Ocean MDT in comparison to fields derived from satellite data. The investigators combined ICESat data with the Arctic Gravity Project (ArcGP) geoid to estimate MDT and compared the results to simulations of MDT from the Miami Isopycnic Coordinate Ocean Model (MICOM) and Polar Ice Prediction System (PIPS) model from the US Naval Postgraduate School. The study revealed large differences between the oceanographic model predictions but an overall qualitative agreement between the satellite observations and the models for large-scale surface features (Fig. 5).

In the coming decade, our capabilities for observing the oceanographic circulation of the Arctic Ocean should be greatly enhanced through the combination of data from new gravity and near-polar altimeter satellites including GOCE, CryoSat-2, and ICESat-2. Each mission will provide valuable new datasets that have the potential to improve the determination of Arctic Ocean MDT and will provide an independent method for validating oceanographic models.
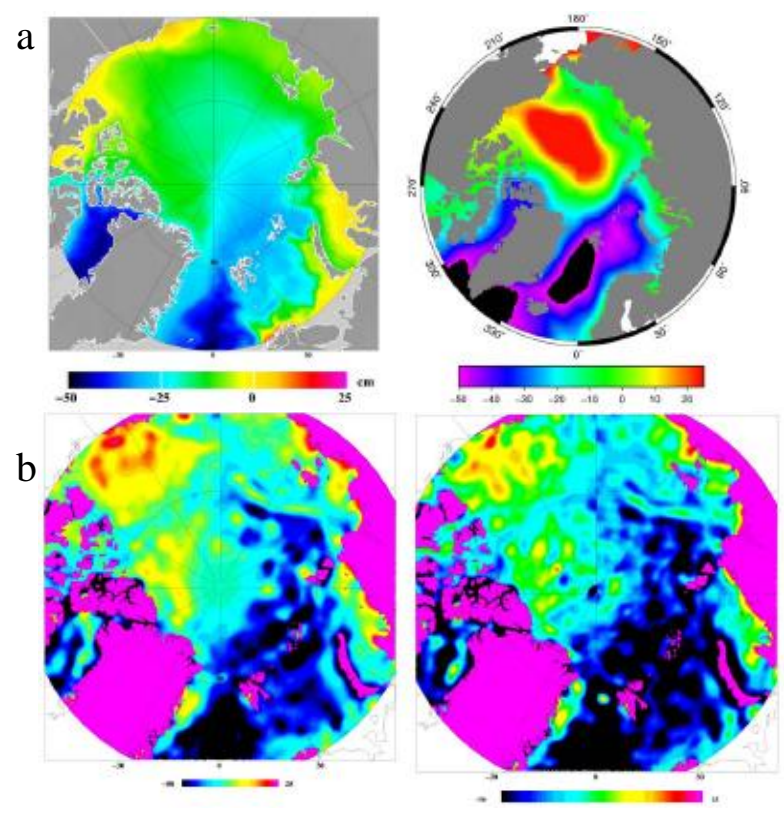

Figure. 5 Comparison of modelled mean dynamic topography (MDT) with that derived from satellite altimetry. (a) MDT from PIPS (left) and MICOM (right) for the period 1995-2003 (PIPS average is for March only). Unit: cm. (b) Low-pass filtered MDT from remote sensing: MDT from MSS with ArcGP geoid (left) and EIGEN-GLAC (right). Unit: $\mathrm{cm}$.

\section{IMPROVEMENT OF ARCTIC TIDE MODELS}

The largest source of SSH variability is the tide, which can reach several meters range in some coastal regions. A secondary source of variability is the inverse barometer effect (IBE), roughly $+1 \mathrm{~cm}$ SSH change per -1 mbar change in air pressure. We need accurate models of tidal SSH and the IBE to remove these highfrequency signals from undersampled satellite altimetry and gravity to reveal general circulation changes. RMS errors of current Arctic tide models are of order $10 \mathrm{~cm}$; compare with signals of a few $\mathrm{cm}$ in SSH changes due to general circulation changes (Figs. 2, 3 and 5).

Accurate modeling of tides is also required because of the tide's known impact on ocean general circulation and sea ice. Holloway and Proshutinsky [11] recently demonstrated that the addition of tides to an Arctic GCM profoundly changes the distributions of temperature and salinity, and associated mean velocity fields, through enhanced mixing, particularly around the basin perimeter. The same study, and earlier work by Kowalik and Proshutinsky [12], demonstrates that the net rates of sea-ice formation and melting are also modified by tides, impacting ice thickness distributions and brine rejection to the upper ocean.

While global depth-integrated ("barotropic") tide models include the Arctic Ocean, the best models are Arctic-specific [12 and 13]. The former (on a $14 \mathrm{~km}$ grid) includes a simple representation of sea-ice coupling to the ocean. The latter model does not represent ice, but is higher resolution $(5 \mathrm{~km})$ and uses assimilation of coastal tide gauges and satellite altimetry to improve performance.

Future improvement of tide model accuracy requires the following: (1) better representation of geometry, especially in the complex passages of the Canadian Archipelago; (2) high-quality data with which to constrain assimilation models; (3) incorporation of realistic sea ice; and (4) evaluation of tidal interactions with modeled general circulation. For (1), general Arctic models are now being developed on finiteelement grids (C. Chen, pers. comm., 2008) that allows for the high resolution required for complex bathymetry at an acceptable overall computational cost. For (2), we require long time series of accurate $\mathrm{SSH}$ and $\mathrm{BP}$ data in key regions of the tidal fields, especially in the deep ocean away from coastal stations. Satellite altimetry in regions of no sea-ice or where returns from leads and open water can be identified can also be assimilated, as can satellite gravity data. For (3), models can incorporate observed sea ice, taking concentration from AMSR-E (Advanced Microwave Scanning Radiometer for EOS (Earth Observing System) and SSM/I (Special Sensor Microwave Image) and thickness from ICESat and ENVISAT (and future satellites Cryosat-2 and ICESat-2). For (4), future modeling of tides should allow for interactions with realistic mean flows, and energy loss through baroclinic tide generation; i.e., 
evaluating tides from a 3-D ocean model including wind and thermohaline forcing.

\section{SEA ICE THICKNESS AND VOLUME}

Sea ice controls the interactions between the ocean and the atmosphere, and the distribution of ice in the Arctic Ocean results from interplays between ice dynamics and thermodynamics. While ice concentration is routinely derived from SSM/I and AMSR, estimates of ice thickness are critical to the understanding of rapid changes in the Arctic ice cover and for model validation. ESA's satellite radar altimeters on ERS-1 and ERS-2 have provided the first space-borne estimates of ice thickness from direct measurements of ice freeboard. Analyses of data for 1993-2001 showed a pan-Arctic ice thickness field that was highly variable from year to year, and highly correlated with the length of the summer melt season [1]. A second time-series, from ESA's ENVISAT satellite (2002-08), suggest a much more stable value for thickness below $81.5 \mathrm{~N}$ but with a large decrease $(25 \mathrm{~cm})$ following the September 2007 ice extent minimum [14].

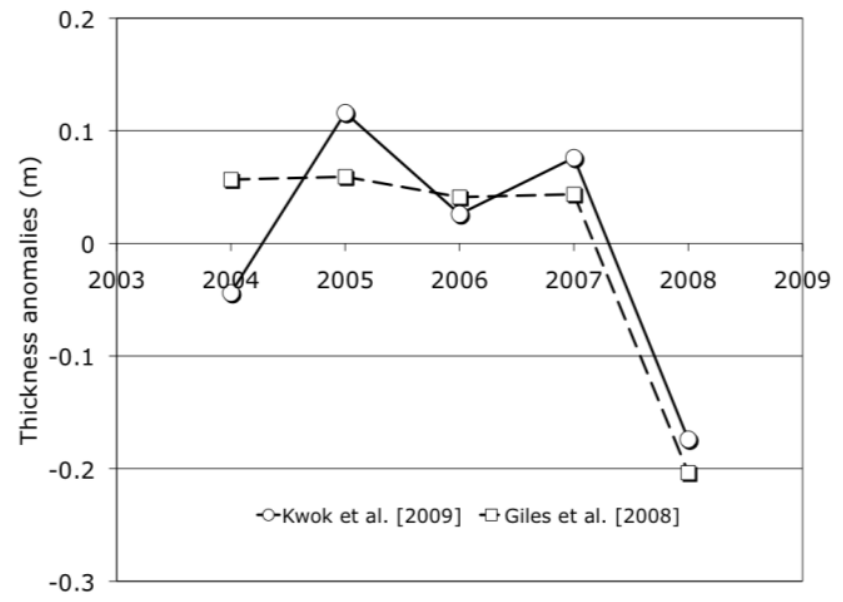

Figure. 6 Comparison of the thickness anomalies derived from the Envisat radar altimeter [12] and the ICESat LIDAR (after [2]).

Lidars (LIght Detection And Ranging instruments) (ICESat and airborne instruments) provide similar opportunities for estimating freeboard and ice thickness. Thickness estimates from ten ICESat campaigns between 2003 and 2008 shows dramatic and rapid thinning, and volume loss of the Arctic Ocean ice cover since 2005 over the entire Arctic Basin [2]. Figure 6 shows the relative agreement between the anomalies in ICESat and ENVISAT ice thickness over the five winters (2004-08) where there is overlapping coverage. Comparisons of altimeter derived ice thickness data on a regional scale suggest accuracies of around $0.5 \mathrm{~m}$ [1] and [2]. Regarding basin-wide scale estimates of ice thickness change, the consistency between laser and radar altimetry (Fig. 6) shows a rather higher precision. Nevertheless further in-situ data on ice thickness, particularly from continuous moorings, will help to better constrain uncertainties in current and future missions. This indicates the possibility of constructing a much longer record of ice thickness changes by combining estimates from the two types of instruments. As mentioned earlier, the upcoming CryoSat-2 and ICESat-2 missions - both with primary scientific objectives of addressing changes in the Arctic sea ice thickness - will, for the first time, provide extensive and routine coverage of this ice parameter of the Arctic Ocean into the next decade.

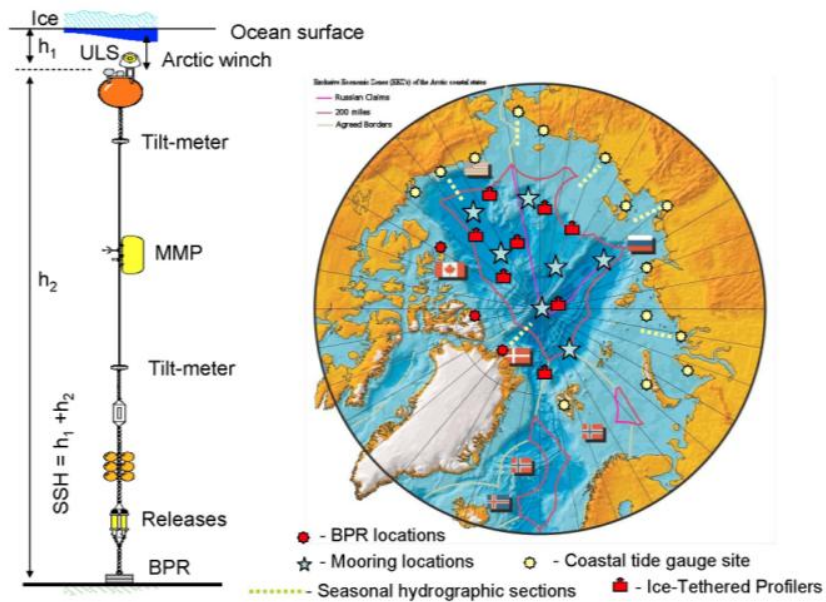

Figure. 7. Mooring components (left) and mooring, tide gauge and bottom pressure recorder (BPR) approximate locations to provide in-situ sustained observations in the Arctic Ocean to complement and validate space-borne measurements of ice thickness and sea surface heights in the Arctic Ocean.

\section{A NETWORK FOR HYDROGRAPHIC SAMPLING}

An essential element for an integrated approach to Arctic oceanography is an in-situ ocean and sea ice observational network to complement and validate the satellite measurements. Some considerations for deploying such a network are discussed here.

In a stratified (or "baroclinic") ocean one can in general have uncorrelated mass and volume changes. This requires the independent observations of ocean mass via gravimetry and ocean volume via altimetry. The difference is the vertically integrated stratification, known as steric sea level (SSL). One can obtain any one of these three terms (SSH, BP, and SSL) from observations of the other two. If all three are available, then a refined error estimate can be obtained on all observations to determine, e.g. the significance of sea level trends [15].

It has traditionally been accepted that SSL change in the Arctic Ocean is a function largely of ocean salinity because the thermal expansion coefficient of seawater at cold arctic temperatures is very small. Water salinity changes at scales from synoptic to decadal and its component which influences sea level variability is 
driven by changes in water volume of the Arctic Ocean (river runoff and water exchange via ocean straits) and regionally by wind via Ekman pumping. Part of these SSL changes is measured by BPRs but the total change is measured by coastal tide gauges and satellites. Ocean temperature may, however, start to play a more important role in the conditions of accelerating Arctic warming. For example, summer water temperature in ice-free regions can exceed the freezing point by $3^{\circ}-5^{\circ}$ $\mathrm{C}$ [16]. Moreover, there is approximately $1^{\circ} \mathrm{C}$ warming of the $\sim 800 \mathrm{~m}$-thick Atlantic water layer resulting in a sea level increase of $\sim 4 \mathrm{~cm}$ relative to climatologic conditions of 1970s. Recent observations also show that the Atlantic water temperature and salinity experience seasonal changes [17] that can affect SSH variability.

Thus, to compute SSH we must have, at a minimum, water temperature and salinity observations within the upper $800 \mathrm{~m}$ in the deep parts of the Arctic Ocean in addition to observations of the fresh Arctic shelves for monitoring freshwater river fluxes. To estimate ocean water mass exchanges via major straits, we also need measurements of currents in the Bering Strait, the principal straits of the Canadian Arctic Archipelago, the Fram Strait, and the Barents Sea Opening.

The most useful observations are repeat surveys, wherein the same measurements are taken at approximately the same time of year at approximately the same location. These can be made by ship/aircraft survey but only in two seasons (March - May by airplanes and July - September by ships). Drifting buoy data can also be useful if they form a dense enough array to provide such repeat coverage; e.g. Krishfield et al. [18].

In addition to these observations, the most important component of an observing network to complement the satellite-derived SSH and sea ice thickness observations should be a net of "reference" observational sites where all components of SSH are measured continuously in the deep ocean regions and along Arctic's coastlines. Figure 7 shows the major elements of this observing system, namely: 1) 5-10 moorings equipped with instruments measuring water temperature, salinity and currents (McLane Mooring Profiler, MMP; and Arctic Winch - a winch attached to the mooring top-float that keeps a subsurface mooring upright. The winch has a wire with a small buoyant float, which carries instruments to measure water temperature, pressure, and salinity. At regular intervals, the small float is released and allowed to rise on a tether either to the ocean surface when no ice is present or to the underside of the ice). Both instruments measure temperature and salinity in the water column above the BPR attached to the mooring anchor. Together, the measurements provide information for calculations of SSL changes. The mooring design shown in Fig. 5 also allows us to measure SSH provided the length of the mooring wire and its tilt, and the distance from the mooring float to the sea surface are known (an upward looking sonar is installed at the top); (2) A set of coastal conventional tide gauges providing observations of SSH which are directly comparable with satellite data (Fig. 5). The coastal tide gauges are currently installed as part of the national coastal observing systems; (3) A set of coastal BPRs to provide sea level observations in the regions where conventional tide gauges do not exist or where their installation is impossible because of severe sea ice conditions; (4) Hydrographic sections crossing shelves to measure water temperature and salinity and to monitor seasonal changes in SSL.

Existing networks for hydrographic observations are typically driven by individual investigators' interests, combined with logistical and political constraints. Ideally, a network designed to systematically monitor sea level and ocean circulation should be guided by a more objective strategy. For example, a set of Observing System Simulation Experiments (OSSE) could be employed to identify optimal in-situ observing site locations required measurement accuracy and frequency, and acceptable levels of uncertainty. The OSSE approach is an established technology (used by agencies such as NASA, NOAA, Météo France, and the Met Office UK) for planning and testing new observational systems and technologies in atmospheric science. The primary objective of OSSEs is to assess the effectiveness of an observing system before it is built. Trade-offs in instrument or network configurations and methods of assimilating a new type of data can be determined with such a system and ultimately result in both time and cost savings. Considering its cost, careful planning of an operational observation system in the Arctic Ocean is needed. The OSSE-style approach will help the design of an effective observing system and identify a minimum of observational sites necessary to reconstruct $\mathrm{SSH}$ and sea ice thickness with expected accuracy. An example of this approach utilized to determine the best locations for monitoring sea ice thickness can be found in [19] and for mooring locations in the Bering Strait in [20]. The OSSE approach also points to the long-term goal of the combined Arctic in-situ and satellite monitoring system; the need for sufficient data to validate Arctic GCMs so as to provide the interpolation of subsurface changes in the Arctic between the necessarily sparse elements of the in-situ arrays.

\section{CONCLUSIONS}

Results from current work that combines satellite and in-situ observations illustrate that significant improvements in our understanding of the Arctic Ocean are about to be realized with existing and forthcoming satellite data sets. Furthermore, the use of these data sets in conjunction with a well-designed in-situ hydrographic sampling network - with judiciously deployed ocean instrument technologies - would ensure the most accurate quantification of the sea level, circulation and mass changes of the Arctic Ocean. Together, an observational network that includes satellite remote sensing, in-situ data acquisition, and 
ice/ocean components considered in companion white papers [21, 22 and 23], will undoubtedly contribute to a new understanding of the Arctic Ocean and its impact on global climate.

\section{ACKNOWLEDGMENTS}

RK performed this work at the Jet Propulsion Laboratory, California Institute of Technology under contract with the National Aeronautics and Space Administration. KG and SWL are funded by the UK National Centre for Earth Observation. LP is funded by NASA grant NNX06AH39G. AP is funded by the National Science Foundation (grant ARC-0806115). MS is funded by the National Science Foundation and NASA's Cryospheric Sciences Program. The views, opinions, and findings contained in this report are those of the authors and should not be construed as an official National Oceanic and Atmospheric Administration or US Government position, policy, or decision.

\section{REFERENCES}

1. Laxon, S. et al. (2003), High interannual variability of sea ice thickness in the Arctic region, Nature, 425, 947-950.

2. Kwok, R., M. Wensnahan, I. Rigor, H. J. Zwally and D. Yi, (2009), Thinning and volume loss of Arctic sea ice: 2003-2008, J. Geophys. Res., doi:10.1029/2009JC005312.

3. Morison, J., J. Wahr, R. Kwok and C. Peralta-Ferriz, 2007, Recent trends in Arctic Ocean mass distribution revealed by GRACE, Geophys. Res. Lett., 34, L07602, doi:10.1029/2006GL029016.

4. Chambers, D.P., 2006, Evaluation of New GRACE TimeVariable Gravity Data over the Ocean. Geophys. Res. Lett., 33(17), LI7603.

5. Vinogradova, N., R. M. Ponte and D. Stammer, (2007), Relation between sea level and bottom pressure and the vertical dependence of oceanic variability, Geophys. Res. Lett., 34, L03608, doi:10.1029/2006GL028588.

6. Morison, J, C. Peralta-Ferriz, J. Wahr and R, Kwok, 2008, Interannual and Seasonal Variability in the Arctic Ocean Observed With GRACE and In Situ Bottom Pressure Measurements, EOS Trans. AGU 89 (53) Fall Meet. Suppl., Abstract of invited oral presentation C14A-01.

7. Thompson, D. W. J. and J. M. Wallace, 1998, The Arctic Oscillation signature in the wintertime geopotential height and temperature fields, Geophys. Res. Lett., 25, 1297-13.

8. Pavlis, N., S.A Holmes, S. C Kenyon and J. K. Factor, 2008, An Earth Gravitational Model to degree 2160: EGM2008, Presented at EGU General Assembly, Vienna Austria, April 2008 (http://earthinfo.nga.mil/GandG/wgs84/gravitymod/egm2008/ocean $\underline{\text { o.html) }}$

9. Tapley, B. D., D. P. Chambers, S. Bettadpur and J. C. Reis, (2003), Large scale ocean circulation from the GRACE GGM01 Geoid, Geophys. Res. Letters, 30(22), doi:10.1029/2003GL018622.
10. Forsberg, R. et al. (2007), Combination of Spaceborne, Airborne and In-Situ Gravity Measurements in Support of Arctic Sea Ice Thickness Mapping, Danish National Space Center Technical Report, No. 7, pp. 137, Copenhagen, Denmark.

11. Holloway G. and A. Proshutinsky, 2007, Role of tides in Arctic ocean/ice climate, J. Geophys. Res., 112, C04S06, doi:10.1029/2006JC003643.

12. Kowalik, Z. and A.Y. Proshutinsky, 1994, The Arctic Ocean Tides, in The Polar Oceans and Their Role in Shaping the Global Environment, Geophysical Monograph 85, edited by O. M. Johannessen, R. D. Muench, and J. E. Overland, AGU, Washington, D. C., pp. 137-158.

13. Padman, L. and S. Erofeeva, 2004, A barotropic inverse tidal Model for the Arctic Ocean, Geophys. Res. Lett., 31(2), L02303, doi:10.1029/2003GL019003.

14. Giles, K. A. et al., (2008), Circumpolar thinning of Arctic sea ice following the 2007 record ice extent minimum, Geophys Res Lett, 35, L22502, doi:10.1029/2008GL035710.

15. Willis, J. K., D. P. Chambers and R. S. Nerem, (2008), Assessing the globally averaged sea level budget on seasonal to interannual timescales, J. Geophys. Res., 113, C06015, doi:10.1029/2007JC004517.

16. Steele M., W. Ermold and J. Zhang, (2008), Arctic Ocean surface warming trends over the past 100 years, Geophys. Res. Lett., 35, L02614, doi:10.1029/2007GL031651.

17. Dmitrenko I. A., I. V. Polyakov, S. A. Kirillov, L. A. Timokhov, I. E. Frolov, V. T. Sokolov, H. L. Simmons, V. V. Ivanov and D. Walsh, (2008), Toward a warmer Arctic Ocean: Spreading of the early 21 st century Atlantic Water warm anomaly along the Eurasian Basin margins, J. Geophys. Res., 113, C05023, doi:10.1029/2007JC004158.

18. Krishfield, R., J. Toole, A. Proshutinsky and M.L. Timmermans, (2008), Automated Ice Tethered Profilers for Seawater Observations under Pack Ice in All Seasons, J. Atmos.Oceanic Technol., 25, 2091-2105.

19. Lindsay, R. W. and J. Zhang, 2006: Arctic Ocean ice thickness: modes of variability and the best locations from which to monitor them, J. Phys. Ocean., 36, 496506.

20. Panteleev, G., M. Yaremchuk and D. Nechaev, (2008), Optimization of mooring observations in Northern Bering Sea, Dynamics of Atmospheres and Oceans, In Press, Corrected Proof, Available online 6 December 2008, ISSN 0377-0265,

doi:10.1016/j.dynatmoce.2008.11.004. (http://www.sciencedirect.com/science/article/B6VCR4V34D70-1/2/5bfeda4ca480721155ce5bff6226b432)

21. Breivik, L. \& Co-Authors (2010). "Remote Sensing of Sea Ice" in these proceedings (Vol. 2), doi:10.5270/OceanObs09.cwp.11.

22. Calder, J. \& Co-Authors (2010). "An Integrated International Approach to Arctic Ocean Observations for Society (A Legacy of the International Polar Year)" in these proceedings (Vol. 2), doi:10.5270/OceanObs09.cwp.14. 
23. Lee, C. \& Co-Authors (2010). "Autonomous Platforms in the Arctic Observing Network" in these proceedings (Vol. 2), doi:10.5270/OceanObs09.cwp.54. 